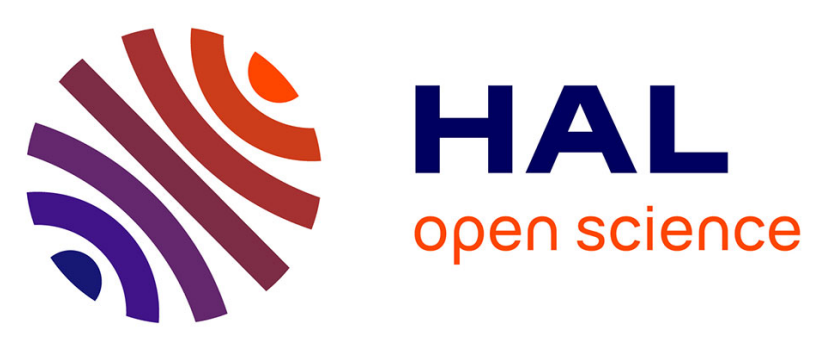

\title{
Integrated Mixed-Model Assembly Line Balancing with Unskilled Temporary Workers
}

Dongwook Kim, Jinwoo Park, Ilkyeong Moon

\section{To cite this version:}

Dongwook Kim, Jinwoo Park, Ilkyeong Moon. Integrated Mixed-Model Assembly Line Balancing with Unskilled Temporary Workers. IFIP International Conference on Advances in Production Management Systems (APMS), Sep 2015, Tokyo, Japan. pp.324-331, 10.1007/978-3-319-22759-7_38 . hal-01431112

\section{HAL Id: hal-01431112 \\ https://hal.inria.fr/hal-01431112}

Submitted on 10 Jan 2017

HAL is a multi-disciplinary open access archive for the deposit and dissemination of scientific research documents, whether they are published or not. The documents may come from teaching and research institutions in France or abroad, or from public or private research centers.
L'archive ouverte pluridisciplinaire HAL, est destinée au dépôt et à la diffusion de documents scientifiques de niveau recherche, publiés ou non, émanant des établissements d'enseignement et de recherche français ou étrangers, des laboratoires publics ou privés.

\section{(c)(1)}

Distributed under a Creative Commons Attribution| 4.0 International License 


\title{
Integrated Mixed- Model Assembly Line Balancing with Unskilled Temporary Workers
}

\author{
${ }^{1}$ Dongwook Kim, ${ }^{1}$ Jinwoo Park, and ${ }^{1}$ Ilkyeong Moon \\ ${ }^{1}$ Department of Industrial Engineering, Seoul National University, Seoul 151-744, Korea \\ E-mail: ikmoonesnu.ac.kr, Fax: +82-2-889-8560
}

\begin{abstract}
This study extends a single-model assembly line balancing problem to an integrated mixed-model assembly line balancing problem by incorporating unskilled temporary workers, who enhance productivity. An integer program that minimizes the sum of total workstation costs and salaries of skilled permanent and unskilled temporary workers within a specific cycle time. The proposed models are based on particular features of a real-world problem including simultaneous assignments of skilled permanent and unskilled temporary workers as well as precedence restrictions for the tasks.
\end{abstract}

Keywords: integer programming, line balancing, mixed-model assembly line, shojinka.

\section{Introduction}

An assembly line is a flow-oriented production system typical of industrial sites that produce large quantities of standardized commodities, but it is also important for producers of low volume diverse or customized products. If only one product is manufactured, then all work pieces are identical and the system is called "a single model assembly line." The names of other assembly lines depend on the types of intermixed units. The different assembly line types, described by different geometric shapes, are characterized in Figure 1. A multi-model assembly line produces a sequence of batches containing units of only one item or a group of similar items with intermediate setup operations, whereas a mixed-model assembly line produces different items in an intermixed sequence. Depending on assembly line types, single, mixed, and multi-model versions of assembly line problems should be applied and studied.

The assembly line balancing problem (ALBP) is used to search for the optimal assignment of assembly tasks to stations under precedence and additional practical constraints. Bryton (1954) introduced the idea of line balancing in his graduate thesis. The first paper on the ALBP was published in 1955. Among the family of ALBPs, the simple assembly line balancing problem (SALBP) is the best known. Assembly line balancing research has traditionally focused on the SALBP that features some restricting

adfa, p. 1, 2011.

(C) Springer-Verlag Berlin Heidelberg 2011 
assumptions. However, it may offer a limited reflection of complex real-world line balancing. A comprehensive review of single-model ALBPs and related solution procedures was provided by Scholl and Becker (2006).

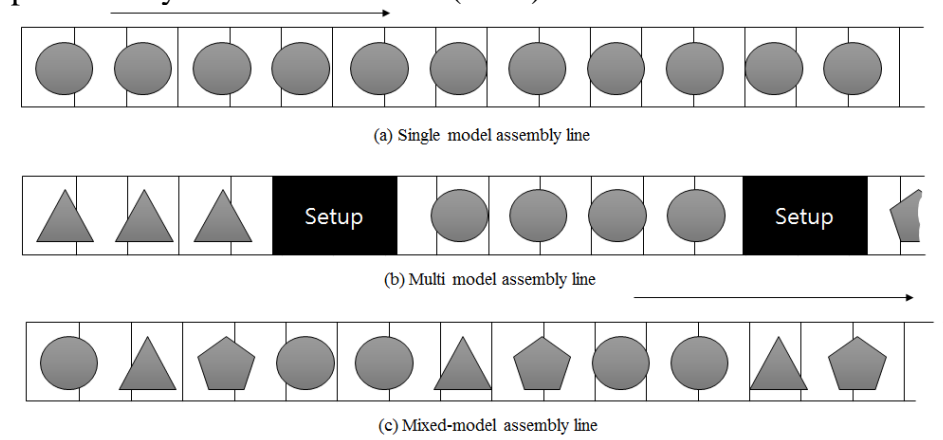

Fig. 1. Different versions of an assembly line

Over time, the needs of customers grow diverse and competition among manufacturers tremendously increases. The installation of a mixed-model assembly line is one of the best responses to this challenging situation, and this methodology has already been widely adopted by industry manufacturers who can use it to meet the diversified demands of their customers without maintaining large inventories or a string of assembly lines. The mixed-model assembly line originated with Toyota, which developed the concept of mixed-model production in the 1960s in response to problems created by line changeovers. The principle of the mixed-model assembly line is quite simple. However, designing the process and system is quite difficult. This study deals with the mixed-model ALBP.

In this paper, we present a mathematical formulation for a mixed-model ALBP with a cost-oriented objective to reduce inefficiency in a manufacturing process, which we reach by considering the employment of unskilled temporary workers. A thorough review of the latest publications did not indicate that a mathematical model has been used to solve a mixed-model ALBP that accounts for the assignment of unskilled temporary workers, which makes up a key component of this study, to obtain balances that minimize potential work overloads. Although Corominas et al. (2008) considered use of temporary workers, they did not account for integrated assembly line balancing. Their objective was to minimize the number of unskilled workers. Moon et al. (2009) studied an integrated ALBP, but they did not consider reducible task times through cooperation of permanent and temporary workers. Moon et al. (2014) is a key reference of this study and they developed an integer program that minimizes the sum of total annual workstation costs and annual salaries of skilled and unskilled workers within a predetermined cycle time. Limitation of their work is that the model can be adopted only for a single model assembly line. This study extends to an integrated mixed-model assembly line balancing problem.

The organization of this paper is as follows: In Section 2, a mathematical model for the integrated mixed-model assembly line balancing situation with unskilled temporary workers is introduced. In Section 3 computational experiment is conducted for the developed mathematical model. Section 4 provides conclusions of this research. 


\section{Mathematical Models}

This study tries to balance a mixed-model assembly line with unskilled temporary workers. Unskilled temporary workers can only perform a subset of all tasks required to manufacture an item, so they cannot be assigned alone to any task. However, they can reduce operation times of completing tasks by cooperating with skilled permanent workers. As a result of this teamwork, the number of workstations needed for performing all tasks can be decreased. However, there is a trade-off between the salaries of unskilled temporary workers and the operation costs of workstations.

Available skill sets for each worker can differ. As a result, both tasks and workers should be optimally assigned. Salaries of workers and operation costs of workstations can be reduced under an efficiently designed workstation. The goal of line balancing is to minimize cost, and it is equivalent to minimizing the sum of the workstation costs and the salaries of skilled permanent and unskilled temporary workers. To solve the industrial problem used in this study, the following assumptions were made for the mathematical model:

(1) A skilled permanent worker cannot be assigned to more than one workstation.

(2) Skilled permanent workers should be assigned to tasks depending on the workstation task sets.

(3) Unskilled temporary workers cannot be assigned alone to any task.

(4) The operation time of tasks can be reduced by assigning an unskilled temporary worker to a task.

(5) At most, one unskilled temporary worker can be assigned to each task to reduce operation time.

(6) Operation and reducible times for production are fixed and known.

(7) Demands during the planning period are fixed and known.

(8) Precedence constraints determine the sequence in which the tasks can be processed.

(9) There is a limit on the number of workers who can occupy each workstation.

Using these assumptions, this study presents a mathematical model for an integrated mixed-model ALBP reflecting operations using unskilled temporary workers. The following notation is presented followed by a description of the objective function and constraints.

Indices:
$i, j$
$k$
$s$
$w$

$$
\begin{gathered}
\text { tasks }(i, j=1,2, \ldots, I) \\
\text { product types }(k=1,2, \ldots, K) \\
\text { workstations }(s=1,2, \ldots, S) \\
\text { skilled permanent workers }(w=1,2, \ldots, W)
\end{gathered}
$$




$$
\begin{aligned}
& \text { Parameters: } \\
& \text { C } \\
& C^{u} \\
& K_{i} \\
& D_{k} \\
& O_{i k} \\
& r_{i k} \\
& P_{(i, j, k)} \\
& T_{w} \\
& O C \\
& S S_{w} \\
& S U \\
& \text { n } \\
& \text { M } \\
& \text { cycle time } \\
& \text { upper limit of total operation time of each workstation } \\
& \text { number of different products that requires task } i \\
& \text { demand of product } k
\end{aligned}
$$

The following two additional parameters are calculated with the above parameters, and Equations (1) and (2) are used for calculation of these added parameters.

$$
\begin{gathered}
o_{i} \begin{array}{l}
\text { aggregated operation time for task } i \text { under demand rates when per- } \\
\text { formed by a skilled permanent worker }
\end{array} \\
\begin{array}{r}
\text { aggregated reducible time for task } i \text { under demand rates when per- } \\
\text { formed by a skilled permanent worker and an unskilled temporary } \\
\text { worker together }
\end{array} \\
r_{i}=\frac{\sum_{k=1}^{K} D_{k} \cdot o_{i k}}{\sum_{k=1}^{K} D_{k}} \\
r_{i}=\frac{\sum_{k=1}^{K} D_{k} \cdot r_{i k}}{\sum_{k=1}^{K} D_{k}}
\end{gathered}
$$

Decision Variables:

F number of workstations to be used in the assembly line 
$X_{i k s w}\left\{\begin{array}{l}1, \text { if task } i \text { for product } k \text { is performed by skilled permanent worker } w \text { at workstation } s \\ 0, \text { otherwise }\end{array}\right.$

$Y_{s w} \quad\left\{\begin{array}{l}1, \text { if skilled permanent worker } w \text { is assigned to workstation } s \\ 0, \text { otherwise }\end{array}\right.$

$Z_{i s} \quad\left\{\begin{array}{l}1, \text { if an unskilled temporary worker is assigned to task } i \text { at workstation } s \\ 0, \text { otherwise }\end{array}\right.$

$A_{i s} \quad\left\{\begin{array}{l}1, \text { if task } i \text { is assigned to workstation } s \\ 0, \text { otherwise }\end{array}\right.$

Objective Function \& Constraints:

$$
\operatorname{Min} O C \cdot F+\sum_{w=1}^{W} S S_{w}\left(\sum_{s=1}^{S} Y_{s w}\right)+S U \cdot \sum_{i=1}^{I} \sum_{s=1}^{S} Z_{i s}
$$

Subject to

$$
\begin{gathered}
\sum_{k=1}^{K} \sum_{s=1}^{S} \sum_{w=1}^{W} X_{i k s w}=K_{i} \quad \forall i \\
\sum_{k=1}^{K} \sum_{w=1}^{W} X_{i k s w}=K_{i} \cdot A_{i s} \quad \forall i, s \\
\sum_{s=1}^{S} \sum_{w=1}^{W} X_{i k s w} \leq M \cdot o_{i k} \quad \forall i, k \\
\sum_{i=1, i \neq T_{w}}^{I} \sum_{k=1}^{K} \sum_{s=1}^{S} X_{i k s w}=0 \quad \forall w \\
\sum_{s=1}^{S} \sum_{w=1}^{W}\left(s \cdot X_{i k s w}-s \cdot X_{j k s w}\right) \leq 0 \quad \forall(i, j, k) \in P_{(i, j, k)} \\
\sum_{i=1}^{I}\left(\sum_{k=1}^{K} \sum_{w=1}^{W} o_{i} \cdot X_{i k s w}-r_{i} \cdot Z_{i s} \sum_{w=1}^{W} X_{i k s w} \quad \forall i, s\right. \\
\sum_{i=1}^{I}\left(\sum_{w=1}^{W} o_{i k} \cdot X_{i k s w}-r_{i k} \cdot Z_{i s}\right) \leq C^{u} \quad \forall k, s \\
\sum_{s=1}^{S} Y_{s w} \leq 1 \quad \forall s
\end{gathered}
$$




$$
\begin{gathered}
\sum_{i=1}^{I} \sum_{k=1}^{K} X_{i k s w} \leq M \cdot Y_{s w} \quad \forall s, w \\
\sum_{w=1}^{W} Y_{s w}+\sum_{i=1}^{I} Z_{i s} \leq n \quad \forall s \\
\sum_{w=1}^{W} X_{i k s w} \leq 1 \quad \forall i, k, s \\
\sum_{s=1}^{S} s \cdot X_{i k s w} \leq F \quad \forall i, k, w \\
X_{i k s w}, \quad Y_{s w}, \quad Z_{i s}, \quad A_{i s} \in\{0,1\}
\end{gathered}
$$

The objective function (3) minimizes the sum of the total workstation costs and the salaries of skilled permanent and unskilled temporary workers. Constraints (4) ensure that every task should be performed by one skilled permanent worker at one workstation. Constraints (5) indicate that the same task for different products should be assigned to the same workstation. Constraints (6) prevent inconsistency of $X_{i k s w}$ which can be greater than zero when $o_{i k}$ is not zero. Constraints (7) prevent skilled worker $w$ from being assigned to a workstation with a task that the worker cannot complete according to the skilled permanent worker's available task set $T_{w}$. Constraints (8) ensure that the precedence relationships between tasks are considered for product $k$. Constraints (9) ensure that an unskilled temporary worker can be assigned to task $i$ only when a skilled permanent worker is also assigned to task $i$. Constraints (10) represent the total operation time under conditions of a demand rate of each workstation that is smaller than a specific time. Constraints (11) represent the total maximum operation time to manufacture product $k$ at each workstation; it is smaller than the specified upper limit. Constraints (12) guarantee that a skilled permanent worker is assigned to exactly one workstation. Constraints (13) demand that a task is assigned to a skilled permanent worker at the workstation; $X_{i k s w}$ can be 1 when a skilled worker is assigned to a workstation. Constraints (14) restrict the number of total workers to one workstation to prevent overcrowding. Constraints (15) ensure that the same task for different product types is assigned to the same worker. Constraints (16) are used to decide the total number of workstations needed. Constraints (17) demonstrate the binary nature of the decision variables.

\section{Computational Experiments}

The mathematical model was solved with FICO Xpress-IVE version 7.3. Computational experiments were conducted with an $\operatorname{Intel}(\mathrm{R}) \mathrm{Xeon}(\mathrm{R}) 3.5 \mathrm{GHz}$ processor with 16GB RAM on the Microsoft Windows Server 2008 R2 operating system. Task precedence sequence diagrams of a test problem are shown in Figure 2. Salaries of skilled 
workers and their available skill sets are shown in Table 1. Demand rates of Product 1 and Product 2 are same in this problem. Reducible times for tasks of each product type are organized in Table 2. Table 3 shows the solution of the test problem. Only two workstations are needed if three unskilled temporary workers are employed in this problem. More experiments will be done in the future research.
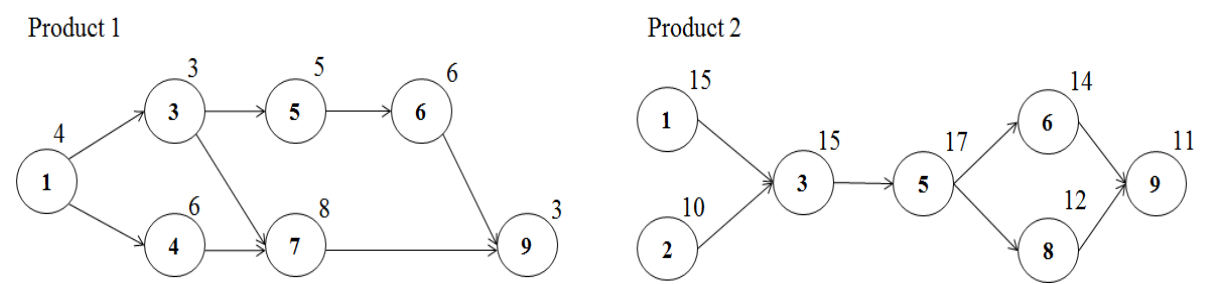

Fig. 2. Task precedence sequence diagrams for 9 tasks and 2 products

Table 1. Available sets and salaries of skilled permanent workers ( 9 and 14 tasks)

\begin{tabular}{|c|c|c|c|c|c|c|}
\hline Tasks & Worker & \multicolumn{4}{|c|}{ Possible Tasks } & Salary \\
\hline \multirow{6}{*}{9} & 1 & 3 & $\overline{6}$ & 8 & & $\overline{\$ \$ 3,800}$ \\
\hline & 2 & 4 & 5 & 6 & 9 & $\$ 4,000$ \\
\hline & 3 & 1 & 5 & 7 & 9 & $\$ 3,700$ \\
\hline & 4 & 2 & 3 & 6 & 8 & $\$ 4,000$ \\
\hline & 5 & 1 & 5 & 8 & & $\$ 3,000$ \\
\hline & 6 & 1 & 2 & 7 & & $\$ 3,000$ \\
\hline
\end{tabular}

Table 2. Reducible times and salaries of unskilled temporary workers

\begin{tabular}{|c|c|c|c|c|}
\hline \multirow{2}{*}{$\begin{array}{l}\text { Number } \\
\text { of tasks }\end{array}$} & \multirow{2}{*}{ Task } & \multicolumn{2}{|c|}{ Reducible time } & \multirow{2}{*}{$\begin{array}{l}\text { Salaries of un- } \\
\text { skilled temporary } \\
\text { workers } \\
\end{array}$} \\
\hline & & Product 1 & Product 2 & \\
\hline \multirow{9}{*}{9} & 1 & 1 & 3 & \multirow{9}{*}{$\$ 1,500$} \\
\hline & 2 & 0 & 3 & \\
\hline & 3 & 1 & 5 & \\
\hline & 4 & 2 & 0 & \\
\hline & 5 & 3 & 4 & \\
\hline & 6 & 2 & 4 & \\
\hline & 7 & 4 & 0 & \\
\hline & 8 & 0 & 3 & \\
\hline & 9 & 1 & 3 & \\
\hline
\end{tabular}

Table 3. Solution of a test problem

\begin{tabular}{|c|c|c|c|c|c|c|c|c|c|c|}
\hline $\begin{array}{c}\text { Task } \\
\text { sequence }\end{array}$ & $i$ & $k$ & $S$ & $O_{i k}$ & $r_{i k}$ & $O_{i}$ & $r_{i}$ & $\begin{array}{c}\text { Cumulative } \\
\text { workstation time }\end{array}$ & $w$ & $\begin{array}{c}\text { Temporary } \\
\text { worker }\end{array}$ \\
\hline 1 & \multirow{2}{*}{1} & 1 & \multirow{2}{*}{1} & 4 & 1 & \multirow{2}{*}{9.5} & \multirow{2}{*}{2} & \multirow{2}{*}{7.5} & \multirow{2}{*}{3} & \multirow[b]{2}{*}{$v$} \\
\hline 2 & & 2 & & 15 & 3 & & & & & \\
\hline
\end{tabular}




\begin{tabular}{|c|c|c|c|c|c|c|c|c|c|c|}
\hline 3 & 2 & 2 & & 10 & 3 & 5 & 3 & 12.5 & 4 & \\
\hline 4 & \multirow{2}{*}{3} & 1 & & 3 & 1 & \multirow{2}{*}{9} & \multirow{2}{*}{3} & \multirow{2}{*}{18.5} & \multirow{2}{*}{4} & \multirow{2}{*}{$\mathrm{O}$} \\
\hline 5 & & 2 & & 15 & 5 & & & & & \\
\hline 6 & \multirow{2}{*}{5} & 1 & & 5 & 3 & \multirow{2}{*}{11} & \multirow{2}{*}{3.5} & \multirow{2}{*}{26} & \multirow{2}{*}{3} & \multirow{2}{*}{$\mathrm{O}$} \\
\hline 7 & & 2 & & 17 & 4 & & & & & \\
\hline 8 & 4 & 1 & \multirow{7}{*}{2} & 6 & 2 & 3 & 2 & 3 & 2 & \\
\hline 9 & \multirow{2}{*}{6} & 1 & & 6 & 2 & \multirow{2}{*}{8} & \multirow{2}{*}{3} & \multirow{2}{*}{11} & \multirow{2}{*}{2} & \\
\hline 10 & & 2 & & 10 & 4 & & & & & \\
\hline 11 & 7 & 1 & & 8 & 4 & 4 & 4 & 15 & 6 & \\
\hline 12 & 8 & 2 & & 12 & 3 & 6 & 3 & 21 & 5 & \\
\hline 13 & \multirow{2}{*}{9} & 1 & & 3 & 1 & \multirow{2}{*}{7} & \multirow{2}{*}{2} & \multirow{2}{*}{28} & \multirow{2}{*}{2} & \\
\hline 14 & & 2 & & 11 & 3 & & & & & \\
\hline
\end{tabular}

\section{Conclusions}

Moon et al. (2009) introduced the integrated ALBP, and this study extends their idea to the mixed-model assembly line and considers simultaneous assignments of skilled and temporary workers. In the production line described herein, the skilled workers have multiple competencies and commensurate salaries; unskilled temporary workers are assigned to help them. A mathematical model was developed by integer linear program for the integrated mixed-model ALBP and the model was designed to minimize total costs, including those associated with operation of workstations and the salaries of skilled permanent and unskilled temporary workers for a specified cycle time. Due to the complexity of the problem, heuristic procedures are needed to solve the problems and it will be done in future research.

\section{References}

1. Bryton, B.: Balancing of a continuous production line. M.S. Thesis, Northwestern University, Evanston, IL (1954)

2. Corominas, A., Pastor, R., Plans, J.: Balancing assembly line with skilled and unskilled workers. Omega, 36, pp. 126-1132 (2008)

3. Monden, Y.: Toyota Production System (2011)

4. Moon, I.K., Logendran, R., Lee, J.H.: Integrated assembly line balancing with resource restrictions. International Journal of Production Research, 47, pp. 5525-5541 (2009)

5. Moon, I.K., Shin, S.H., Kim, D.W.: Integrated assembly line balancing with skilled and unskilled workers. IFIP Advances in Information and Communication Technology, 438 (1), pp. 459-466 (2014)

6. Scholl, A. and Becker, C., State-of-the-art exact and heuristic solution procedures for simple assembly line balancing. European Journal of Operational Research, Vol. 168, p.666-693, 2006. 